BULLETIN Bulletin hispanique

HISPANIQUE Université Michel de Montaigne Bordeaux

114-1 | 2012

Varia

Rafael Alarcón, Una rana viajera. Las crónicas y los libros de viaje de Julio Camba (Camba en quince lecciones)

Renacimiento, Sevilla, 2010

Antonio Martín Ezpeleta

\title{
OpenEdition
}

Journals

Edición electrónica

URL: http://journals.openedition.org/bulletinhispanique/1962

DOI: 10.4000/bulletinhispanique.1962

ISSN: 1775-3821

Editor

Presses universitaires de Bordeaux

Edición impresa

Fecha de publicación: 1 junio 2012

Paginación: 488-490

ISBN: 978-2-86781-812-7

ISSN: 0007-4640

Referencia electrónica

Antonio Martín Ezpeleta, « rafael Alarcón, Una rana viajera. Las crónicas y los libros de viaje de Julio

Camba (Camba en quince lecciones) », Bulletin hispanique [En línea], 114-1 | 2012, Publicado el 27 mayo

2013, consultado el 10 diciembre 2020. URL : http://journals.openedition.org/bulletinhispanique/1962

; DOI : https://doi.org/10.4000/bulletinhispanique.1962

Este documento fue generado automáticamente el 10 diciembre 2020.

Tous droits réservés 


\section{Rafael Alarcón, Una rana viajera. Las crónicas y los libros de viaje de Julio Camba (Camba en quince lecciones)}

Renacimiento, Sevilla, 2010

Antonio Martín Ezpeleta

\section{REFERENCIA}

Rafael Alarcón, Una rana viajera. Las crónicas y los libros de viaje de Julio Camba (Camba en quince lecciones). - Sevilla, Renacimiento, 2010

1 El profesor Rafael Alarcón, autor de numerosos estudios sobre la literatura española de la primera mitad del siglo XX especialmente y editor de algunos de los poetas más sobresalientes de este periodo, como Manuel Machado, Antonio Machado, Juan Ramón Jiménez o recientemente Luis Felipe Vivanco, nos presenta ahora una monografía sobre los libros y crónicas de viaje del genial Julio Camba (Vilanova de Arousa, Pontevedra, 1882-Madrid, 1962). Se trata de un estudio articulado en quince lecciones como advierte el subtítulo, que amplía notablemente un trabajo anterior de Alarcón: «Los libros de viaje en la primera mitad del siglo XX. Julio Camba: la rana viajera», publicado en el importante libro de autoría colectiva Los libros de viaje. Realidad vivida y género literario, editado por Leonardo Romero Tobar y Patricia Almarcegui (Madrid, Akal, 2005, pp. 158-195).

2 La obra de Julio Camba es aplaudida por los expertos, pero curiosamente no contamos con todos sus textos en ediciones modernas (no sería mala idea, pues, reeditar y poner al día sus opera omnia, cuya agotada edición es de 1948). Acaso esta sea la razón por la cual el autor de La rana viajera no es ni mucho menos uno de los autores más conocidos de su generación, la denominada novecentista, ya de suyo bastante eclipsada por las cifras del 98 y 27. Por tanto, parece acertado el tono divulgativo del estudio de Alarcón, que va desmenuzando en diferentes «lecciones» (que podrían haberse titulado para 
facilitar la búsqueda de información a partir del índice) la contextualización del autor y su obra y el análisis del corpus de crónicas y libros de viaje que preparó Camba en sus viajes por Londres, París, Alemania, Suiza, Italia, Portugal y Estados Unidos, relegando a las casi cuatrocientas notas al pie los comentarios más eruditos (el grado de erudición del estudio es, en fin, más que notable; especialmente rica es la parte referida a la recepción de Nueva York por los escritores, donde el autor recuerda a escritores coetáneos a Camba como Maeztu, Morand, Moreno Villa o, entre otros, Juan Ramón Jiménez, autores, por lo demás, recurrentes en las notas de todo el libro, junto a Pla, Campoamor, Blasco Ibáñez, Madariaga, Miquelarena, Martínez Sierra, Luis de Oteyza, Los cuadros de viaje de Heine, las reflexiones de El destierro del propio Camba...). Todo ello viene perfectamente ilustrado con numerosas citas textuales de Camba, dotando al estudio de cierto carácter de antología. Pero vayamos por partes.

En las dos primeras lecciones se nos presenta la vida y la obra de Julio Camba, y se completa además un estado de la cuestión de los trabajos dedicados al autor. Se insiste sobre todo en los dos aspectos que más nos interesan para comprender las crónicas de Julio Camba: su inquietud viajera y su trabajo como periodista, ambos reunidos en su tarea como corresponsal. Esta vez no nos encontramos con un escritor que se ve forzado a escribir en los periódicos, como tantas veces ha ocurrido y ocurre con los intelectuales. Se observa cómo Julio Camba sentía vocacionalmente esta tarea de corresponsal, tarea muy popular por cierto en su época (la desarrollaron también otros escritores como, por ejemplo, Ramiro de Maeztu, Ramón Pérez de Ayala, Salvador de Madariaga o, en fin, Josep Pla, de quien se citan por cierto numerosos textos muy bien traídos a colación a lo largo del estudio). Casaba muy bien, claro, con ese carácter aventurero de Julio Camba que lo llevó a pasar la mayor parte de su vida de país en país: Argentina (de donde fue deportado por anarquista), Turquía, Francia, Inglaterra, Portugal o, entre otros, Alemania o Estados Unidos, países estos últimos que tuvo que abandonar debido a acontecimientos tan terribles e importantes como la I Guerra Mundial o el crack del 29. Sus crónicas fueron publicadas por numerosos periódicos ( $E l$ País, España Nueva, Los Lunes de El Imparcial, La Correspondencia de España, El Mundo, ABC... ), que reflejaron su curiosidad y gran capacidad de observación, amén de su característico sentido del humor.

4 Las lecciones III y IV del estudio presentan el género de los libros de viaje y con más detalle la crónica (comentarios sobre hechos relacionados con la actualidad, escritos con una conciencia creadora, personal y con la idea de fomentar una opinión crítica, inédita, etcétera [p.26]). Esta caracterización, sin embargo, no se queda en una especulación teórica; sino que se aprovechan las citas del propio Camba sobre el género para ilustrar el asunto. Las notas irónicas son ya evidentes desde el primer momento: "iDesconfíe el lector de los artículos largos! Cuando un periodista tiene algo que decir, le basta con veinte líneas. Si lleva tres columnas, es que no dice nada absolutamente. Y para no incurrir en el riesgo de no decir nada, yo acabo aquí mismo» (ibíd.).

5 Las lecciones V, VI y VII se dedican a estudiar el lenguaje y poética de Camba en sus crónicas, con especial atención a los recursos que utiliza para crear ese humor absurdo tan particular («El hombre no es fundamentalmente malo ni fundamentalmente bueno, sino fundamentalmente absurdo» [p. 80]). En estas páginas queda bien patente, también a partir de los textos del propio autor, su consideración del oficio de escritor y de cronista, así como su defensa del periodismo. Todo ello, no obstante, se hace con ese tono jocoserio $\tan$ característico, que parece quitar trascendencia al asunto: 
«Intelectual quiere decir hombre que trabaja con la inteligencia, y ¿qué escritor trabaja con inteligencia en España? Si hay alguno, lo siento por él, ya que la inteligencia es la muerte de la personalidad. [...] Cada cual, señores, se saca la literatura de donde puede [...]» (pp. 63-64).

6 La lección VIII es especialmente relevante, pues es donde se analizan las costumbres que busca Camba, ese intento de captar el particular carácter nacional de cada país que visita. Esa legitimación del Volksgeist en ocasiones, no obstante, parece ridiculizarse, ya que se elevan a categoría impresiones o detalles absurdos, como que los ingleses son el prototipo de turistas («Un hotel donde no haya un inglés no parecerá un hotel. [...] El inglés es turista por naturaleza» [p.55]), que los alemanes siempre pronuncian la palabra «Kolossal» delante de cualquier monumento (p.56) o que los norteamericanos miran todas las cosas (una catedral, una montaña...) con aire comprador (p. 57).

7 La lección IX se dedica a presentar y estudiar la estructura de los libros conformados por la reunión de las crónicas previamente publicadas en la prensa, que son los que en sucesivas lecciones se estudiaran por separado. Así, nos encontramos, de un lado, con los libros Londres (1916) y Alemania, impresiones de un español (1916), dedicados a un solo país, igual que sucede con Un año en otro mundo (1917) y La ciudad automática (1934), que versan sobre Estados Unidos y especialmente Nueva York; y de otro, los que recogen un viaje por diferentes países europeos, como es el caso de Playas, ciudades y montañas (1916), La rana viajera (1920) o Aventuras de una peseta (1923). Como podemos comprobar, estas obras vienen ordenadas por los países que visita principalmente, para luego ordenarse internamente por temas, sacrificando incluso el orden temporal, tal y como explica Alarcón. La estructura acumulativa de estos libros de crónicas de Camba, así como su relación con las características propias del (macro)género de los libros de viaje, son otras de las cuestiones que tienen su lugar en este capítulo.

8 À partir de aquí, se estudia en Una rana viajera uno por uno los países que visita Camba (Inglaterra y Alemania en las lecciones X y XI respectivamente; Suiza, Italia y Portugal, en la XII; y Estados Unidos, en las lecciones XIII y XIV), conformando a su vez una antología ad hoc de fragmentos de las crónicas de Camba en cada capítulo. El resultado es la ilustración de muchos de los aspectos mencionados en las páginas previas, sobre todo lo referido a los tópicos nacionales. Además, todo ello es enriquecido con la inclusión de breves comentarios de texto, que vienen a poner de relieve la explicada poética del autor, donde la desautomatización por medio del humor y el absurdo son sus notas más sobresalientes.

9 La lección XV, por último, recapitula algunas nociones y especula sobre cómo operan los tópicos y las costumbres nacionales en las crónicas de Camba como marco caracterizador por oposición de la propia nación española. Y es que, como es sabido, el encuentro con el otro, con diferentes culturas, es también un ejercicio de autoconocimiento personal y nacional. En este sentido, la burlona europeización de un castizo personaje con el que Camba se identifica no deja de ser también una llamada de atención a los españoles, una invitación a la reflexión y cambio muy propios de la época. Por lo demás, se destaca que el conocido esquema de la mirada ingenua del extranjero y el encuentro con el otro, que es por supuesto el modelo literario, no es infrecuente descubrirlo subvertido en las crónicas de Camba, pues nuestro autor añade un componente fundamental: el humorismo, que gusta desmitificar y hasta ridiculizar este modelo. Así, no nos debe sorprender cuando el autor relativiza irónicamente los tópicos y costumbres nacionales (cuando afirma, por ejemplo, que la Torre Eiffel podría 
estar perfectamente en Berlín...), cuando no el mismo ejercicio de corresponsal o las diferentes máscaras que utiliza el narrador, en palabras de Alarcón. Cierra el libro, por último, la bibliografía ordenada de Julio Camba y una selección de los estudios más importantes dedicados al autor y su obra.

Concluyamos también nosotros insistiendo en que Una rana viajera. Las crónicas y los libros de Julio Camba es una obra para diferentes tipos de lectores, no solamente especialistas. El estudio de Alarcón compagina perfectamente la cumplida información sobre el autor, la contextualización y recepción de los libros que conforman el corpus, junto al completo comentario literario de las crónicas de Camba, todo ello llevado a cabo de una manera amena y concediendo todo el protagonismo a los textos de Camba. Este análisis, como hemos explicado, se aprovecha de diferentes acercamientos teóricos, como el estudio de los tópicos y las referencias intertextuales, los aspectos narratológicos y estilísticos, con especial mención a las diferentes apariciones del humor en estos textos, el cual lleva a Camba a flirtear con la puesta en crisis del género y el pacto literario -al fin y al cabo, estamos en la época de las vanguardias- y también a ridiculizar aspectos culturales de las naciones que visita, la española e incluso al propio cronista, que gusta reírse de sí mismo. Este completo estudio es de lectura realmente agradable, a la que contribuyen las numerosas y divertidas citas de los textos de Camba. Las notas sobre el contexto y las referencias más eruditas, como decíamos, están presentes en el estudio, pero el peso del análisis es estrictamente literario. No podía ser de otra manera, al tratarse de un autor que afirmaba valientemente: «En literatura casi nada es realidad, y casi todo literatura» (p. 68). 